\title{
Urinary Complication
}

National Cancer Institute

\section{Source}

National Cancer Institute. Urinary Complication. NCI Thesaurus. Code C115772.

Any disorder of the organs of the urinary system occurring as a consequence of injury to the urinary system. 